\title{
Linezolid-Induced Thrombocytopenia Is Caused by Suppression of Platelet Production via Phosphorylation of Myosin Light Chain 2
}

\author{
Masataka Tajima ${ }^{a}$ Yoshinori Kato, ${ }^{a}$ Jun Matsumoto, ${ }^{a}$ Iori Hirosawa,${ }^{a}$ Mariko Suzuki, ${ }^{a}$ \\ Yuki Takashio, ${ }^{a}$ Mao Yamamoto,${ }^{a}$ Yoshifumi Nishi, ${ }^{b}$ and Harumi Yamada*,a,b \\ ${ }^{a}$ Department of Pharmaceutical Sciences, International University of Health and Welfare; 2600-1 Kita-kanemaru, \\ Ohtawara, Tochigi 324-8501, Japan: and ${ }^{b}$ Graduate School of Pharmaceutical Sciences, International University of \\ Health and Welfare; 2600-1 Kita-kanemaru, Ohtawara, Tochigi 324-8501, Japan. \\ Received May 25, 2016; accepted August 17, 2016
}

Linezolid (LZD) is an antimicrobial that is commonly used for treatment of vancomycin-resistant Enterococci and methicillin-resistant Staphylococcus aureus infections. However, the development of thrombocytopenia, one of the most frequent adverse side effects of this antimicrobial, can lead to discontinuation of LZD treatment. While clinical studies indicate that risk factors for the development of LZD-induced thrombocytopenia include treatment for $>14$ consecutive days, renal dysfunction, and chronic liver disease, the fundamental mechanism governing the pathogenesis of this disorder remains unclear. In this study, we aimed to elucidate the mechanism of LZD-induced thrombocytopenia by investigating the impact of LZD treatment on platelet destruction and production using rat platelet-rich plasma (PRP) and human immortalized cell lines, respectively. Compared to the control population, an increase in lactate dehydrogenase release was not detected upon exposure of rat PRP to varying concentrations of LZD, indicating that this compound is not cytotoxic towards platelets. Meanwhile, LZD treatment resulted in a significant dose-dependent increase in the proliferation of HEL human erythroleukemia and MEG-01 human megakaryoblast cells in vitro, but did not influence the differentiation of these cell lines. Lastly, LZD treatment yielded elevated levels of phosphorylation of myosin light chain 2 (MLC2), which regulates platelet release, in MEG-01 cells. Based on these results, we speculate that LZD induces thrombocytopenia by promoting MLC2 phosphorylation and thereby suppressing the release of platelets from mature megakaryocytes. These findings provide the first insight into the mechanism of LZD-mediated thrombocytopenia and may facilitate the development of strategies to treat and/or prevent this disease.

Key words thrombocytopenia; linezolid; adverse effect; mechanism; myosin light chain

Linezolid (LZD), a member of the oxazolidinone class of antibacterial agents, exhibits a high level of clinical efficacy against vancomycin-resistant Enterococci (VRE) and methicillin-resistant Staphylococcus aureus (MRSA). LZD functions by binding the $50 \mathrm{~S}$ ribosomal subunit, thereby inhibiting the formation of a functional $70 \mathrm{~S}$ initiation complex. ${ }^{1)}$ Due to this unique mechanism of action, there is thought to be no crossresistance between LZD and other conventional antibiotics. Furthermore, LZD is expected to maintain its therapeutic efficacy in tissues associated with poor blood flow (e.g., bronchoalveolar lavage, inflammatory fluid, bone, fat, muscle, and cerebrospinal fluid), making it an ideal option for treatment of deep-tissue infections. ${ }^{2-5}$ Lastly, as the bioavailability of LZD is approximately $100 \%,{ }^{6}$ it is possible to switch from intravenous to oral administration while using the same dosage. Although these advantages make LZD an excellent antimicrobial agent, administration of LZD has been reported to cause adverse side effects such as gastrointestinal disturbances, thrombocytopenia, decreased hemoglobin/hematocrit levels, and cutaneous reactions. ${ }^{7)}$ Of these, the incidence of thrombocytopenia is particularly high $(7.4-64.7 \%){ }^{7-11)}$ and the onset of this condition can lead to the discontinuation of LZD treatment. Recent clinical studies demonstrated that risk factors for LZD-induced thrombocytopenia include treatment for $>14$ consecutive days, ${ }^{12,13)}$ renal dysfunction, ${ }^{8,9,14)}$ and chronic liver disease. ${ }^{15,16)}$

The primary causes of thrombocytopenia can be broadly categorized into two mechanisms: increased consumption/ destruction or reduced production of platelets. For example, while heparin and quinine are known to cause thrombocytopenia by accelerating platelet destruction via an immunologic reaction, ${ }^{17,18)}$ chemotherapeutic agents such as gemcitabine, cisplatin, and carboplatin decrease platelet production via myelosuppression. ${ }^{19)}$ Although LZD induces myelosuppression, this compound is more frequently associated with thrombocytopenia than pancytopenia. Furthermore, few reports have indicated that administration of LZD results in stimulation of the immune response. While the fundamental mechanism governing LZD-induced thrombocytopenia remains unclear, it is likely that LZD induces thrombocytopenia by affecting the consumption/destruction and/or production of platelets.

In this study, to elucidate the mechanism of LZD-induced thrombocytopenia, direct platelet cytotoxicity was measured using rat platelet-rich plasma (PRP), and the impact of LZD on platelet production was investigated using human erythroleukemia and megakaryoblastic cell lines.

\section{MATERIALS AND METHODS}

Materials LZD, menadione (MEN), and phorbol 12-myristate 13-acetate (PMA) were purchased from Sigma-Aldrich Corp. (St. Louis, MO, U.S.A.), and panobinostat (PAN) was purchased from LC Labs. (Woburn, MA, U.S.A.). Polyclonal rabbit anti-myosin light chain 2 (MLC2), polyclonal rabbit anti-phospho-MLC2, and goat anti-rabbit immunoglobulin G (IgG) horseradish peroxidase (HRP)-linked antibodies were 
purchased from Cell Signaling Technology (Danvers, MA, U.S.A.). The cytotoxicity detection kit and the Cell Counting Kit-8 were purchased from Roche Diagnostic Corp. (Basel, Switzerland) and Dojindo Laboratories (Kumamoto, Japan), respectively. ISOGEN was purchased from Nippon Gene, Co. (Tokyo, Japan). The high-capacity cDNA synthesis kit and Power SYBR Green PCR Master Mix were purchased from Applied Biosystems (Waltham, MA, U.S.A.). Pierce BCA Protein Assay kit was purchased from Thermo Scientific (Waltham, MA, U.S.A.). Primers were purchased from Invitrogen Corp. (Waltham, MA, U.S.A.). All other reagents were of the highest grade commercially available.

Animals Eight-week-old male Wistar-ST rats were purchased from Japan SLC, Inc. (Hamamatsu, Japan). Rats were housed under a $12 \mathrm{~h}$ light/dark cycle and given food and water ad libitum for 1 week for acclimatization. The present study was approved by the Experimental Animal Care and Use Committee of the International University of Health and Welfare.

Preparation of PRP PRP was prepared using a previously published procedure, but with modifications. ${ }^{20,21)}$ Briefly, blood was collected from the abdominal vena cava of rats after diethyl ether-induced anesthesia using a syringe containing $3.8 \%$ sodium citrate [9:1 dilution $(\mathrm{v} / \mathrm{v})$ of blood: $3.8 \%$ sodium citrate], and PRP was obtained by centrifugation at $150 \times \boldsymbol{g}$ for $15 \mathrm{~min}$ at room temperature. PRP was diluted 40 fold in suspension buffer [134 mM NaCl, $2.9 \mathrm{~mm} \mathrm{KCl}, 1.0 \mathrm{~mm}$ $\mathrm{MgCl}_{2}, \quad 10.0 \mathrm{~mm} \quad$ 2-[4-(2-hydroxyethyl)piperazin-1-yl]ethanesulfonic acid (HEPES), $5.0 \mathrm{~mm}$ glucose, $12.0 \mathrm{~mm} \mathrm{NaHCO}_{3}$, $0.34 \mathrm{~mm} \mathrm{Na}_{2} \mathrm{HPO}_{4}$, and $0.3 \%$ bovine serum albumin (BSA) $(\mathrm{pH}$ 7.4)] and the platelet concentration was adjusted to approximately $7.4 \times 10^{6}$ platelets $/ \mathrm{mL}$.

Measurement of Lactate Dehydrogenase (LDH) Leakage from Platelets The cytotoxicity of LZD was determined by measuring the release of $\mathrm{LDH}$ from platelets. For these analyses, diluted PRP was incubated with $0-200 \mu \mathrm{M}$ LZD or with $40 \mu \mathrm{M}$ MEN (positive control), which disrupts platelets, at least in part, via oxidative damage, ${ }^{20,21)}$ for $4 \mathrm{~h}$ at $37^{\circ} \mathrm{C}$. Subsequently, LDH leakage from platelets was measured using a cytotoxicity detection kit, according to the manufacturer's instructions. Briefly, $100 \mu \mathrm{L}$ of sample was added to $100 \mu \mathrm{L}$ of reaction mixture and then incubated for $10 \mathrm{~min}$ at room temperature. After incubation, $50 \mu \mathrm{L}$ of stop solution was added, and the absorbance of the mixture at $490 \mathrm{~nm}$ was measured using a microplate reader (SH-1000 Lab; Corona Electric Co., Ltd., Hitachinaka, Japan). Total LDH activity was determined using platelets disrupted by incubation in lysis solution, and the level of $\mathrm{LDH}$ leakage was expressed as a percentage of total activity.

Cell Culture The human erythroleukemia cell line (HEL) and the MEG-01 human megakaryoblastic cell line were obtained from the Japanese Collection of Research Bioresources (JCRB) Cell Bank (Osaka, Japan). Cells were cultured in RPMI-1640 medium containing 10\% fetal bovine serum (FBS), $10000 \mathrm{U} / \mathrm{mL}$ penicillin, and $10000 \mu \mathrm{g} / \mathrm{mL}$ streptomycin at $37^{\circ} \mathrm{C}$ in a humidified $5 \% \mathrm{CO}_{2}$ incubator.

Cell Proliferation Assay HEL and MEG-01 cells were seeded in 96-well plates at $5 \times 10^{3}$ cells/well and treated with $0-400 \mu \mathrm{M} \mathrm{LZD}$ for $3 \mathrm{~d}$. After incubation, $10 \mu \mathrm{L}$ of cellcounting kit- 8 was added to each well. The plates were then incubated for $2 \mathrm{~h}$ at $37^{\circ} \mathrm{C}$ and the absorbance of each well at
$450 \mathrm{~nm}$ was measured using a microplate reader.

Cell Differentiation and Total RNA Extraction The mRNA expression level of glycoprotein (GP)IIIa was measured to assess the effect of LZD on the megakaryocytic differentiation of HEL and MEG-01 cells. HEL and MEG-01 cells were seeded in $60 \mathrm{~mm}$ dishes at a density of $1 \times 10^{6}$ and $5 \times 10^{5}$ cells/dish, respectively. Cells were then co-treated with $10 \mathrm{~nm}$ PMA and 0-200 $\mu \mathrm{m}$ LZD for $3 \mathrm{~d}$, and total RNA was extracted using ISOGEN reagent, according to the manufacturer's instructions. The resulting solutions were diluted 50 -fold in Tris-ethylenediaminetetraacetic acid (EDTA) (TE) buffer, and the purity and concentration of the RNA (ng/ $\mu \mathrm{L})$ were calculated by measuring the absorbance at 260 and $280 \mathrm{~nm}$ using a Gene Quant Pro spectrophotometer (Amersham Biosciences, Little Chalfont, U.K.).

Real-Time Reverse Transcription (RT)-PCR cDNA was synthesized from $1 \mu \mathrm{g}$ of total RNA using a high-capacity cDNA synthesis kit and diluted 20-fold in TE buffer. The mRNA expression levels of GPIIIa and glyceraldehyde3-phosphate dehydrogenase (GAPDH) were measured using the following primers: GPIIIa forward 5'-TGGTCC TGC TCTCAGTGA TG-3', GPIIIa reverse 5'-GAA TTC TTT TCGGTCGTGGA-3'; GAPDH forward 5'-GAAGGTGAA GGT CGG AGT C-3', GAPDH reverse 5'-GAA GAT GGT GAT GGGATT TC-3'. PCR reactions were carried out in 96-well PCR plates and were comprised of $12.5 \mu \mathrm{L}$ of Power SYBR Green PCR Master Mix, $1.5 \mu \mathrm{L}$ of each primer $(5 \mathrm{pmol} / \mu \mathrm{L})$, $2 \mu \mathrm{L}$ of cDNA in TE buffer solution, and $7.5 \mu \mathrm{L}$ of RNase-free water. The thermocycler conditions were as follows: denaturation at $95^{\circ} \mathrm{C}$ for $15 \mathrm{~s}$, annealing at $56^{\circ} \mathrm{C}$ for $30 \mathrm{~s}$, and elongation at $72^{\circ} \mathrm{C}$ for $30 \mathrm{~s}$. The fluorescence intensity of the amplification process was monitored using 7300 sequence detection system software (Applied Biosystems). The GPIIIa mRNA levels were normalized against that of GAPDH.

Western Blot Analyses MEG-01 cells were treated with $0-200 \mu \mathrm{M}$ LZD or $20 \mathrm{~nm}$ PAN (positive control) ${ }^{22}$ for $24 \mathrm{~h}$ and total protein was extracted according to the method described by Bishton et $a .^{22)}$ Briefly, cells were rinsed with phosphate buffered saline (PBS) and lysed by suspension in Triton $\mathrm{X}$ lysis buffer [20 mm Tris ( $\mathrm{pH} 7.4$ ), $135 \mathrm{~mm} \mathrm{NaCl}, 1.5 \mathrm{~mm} \mathrm{MgCl}_{2}$, $1 \mathrm{~mm}$ ethylene glycol tetraacetic acid (EGTA), 10\% glycerol, and $1 \%$ Triton X-100] containing protease and phosphatase inhibitors for $30 \mathrm{~min}$ on ice. Lysates were then centrifuged at $12000 \times \boldsymbol{g}$ for $15 \mathrm{~min}$ at $4^{\circ} \mathrm{C}$ and supernatants were harvested. Protein concentrations were measured using the Pierce BCA Protein Assay kit with BSA as the standard. Proteins were separated by $15 \%$ sodium dodecyl sulfate polyacrylamide gel electrophoresis (SDS-PAGE) using the Laemmli method, ${ }^{23}$ ) and electrophoretically transferred to polyvinylidene fluoride (PVDF) membranes. Membranes were blocked by incubation with $2 \% \mathrm{BSA}$ in Tris-buffered saline containing $0.1 \%$ Tween 20 (TBS-Tween) for $1 \mathrm{~h}$ at room temperature, and then incubated with a primary antibody specific to phosphorylated MLC (phospho-MLC; $1: 500)$ or to total MLC (1:1000) in 2\% BSA TBS-Tween at $4^{\circ} \mathrm{C}$ overnight. After washing with TBSTween, membranes were incubated with a peroxidase-conjugated anti-rabbit IgG secondary antibody for $1 \mathrm{~h}$ at room temperature. After again washing with TBS-Tween, membranes were incubated with the enhanced chemiluminescence (ECL) plus detection reagent and visualized using a ChemiDoc XRS device (Bio-Rad, Hercules, CA, U.S.A.). Band-intensities were 
analyzed with Quantity One software (Bio-Rad).

Statistical Analysis Data are expressed as the mean \pm standard deviations (S.D.) or standard errors (S.E.). Dunnett's test for multiple comparisons was utilized to assess the statistical significance of differences between results. $p<0.05$ was considered significant for all tests.

\section{RESULTS}

LZD Does Not Exert Cytotoxic Effects on Platelets To investigate the cytotoxic effects of LZD toward platelets, rat PRP samples were exposed to different concentrations of LZD and cytotoxicity was evaluated by measuring LDH leakage levels. Plasma typically contains small amounts of LDH, which is spontaneously released from various tissues or hematopoietic cells, resulting in a baseline level of LDH activity. Indeed, the untreated control group exhibited approximately $5 \% \mathrm{LDH}$ activity compared to the $100 \%$ lysis control. While treatment with MEN (positive control) resulted in complete disruption of the platelets, none of the LZD concentrations tested induced LDH leakage from the PRP samples (Fig. 1), indicating that LZD was not cytotoxic towards platelets.

LZD Enhances Proliferation, but Does Not Affect Differentiation, of HEL and MEG-01 Cells We next investigated the impact of LZD on the proliferation of HEL and MEG-01 cells and on differentiation in the platelet production process. LZD treatment resulted in a dose-dependent increase in HEL cell proliferation, with the cells exposed to a high dose $(200 \mu \mathrm{M})$ of LZD exhibiting a $90 \%$ increase in proliferation compared to the control group (Fig. 2). Likewise, the proliferation of MEG-01 cells was increased by LZD treatment.

Meanwhile, treatment with PMA resulted in increased GPIIIa mRNA expression in both HEL and MEG-01 cells compared to the control, which was accompanied by differentiation into mature megakaryocytes (Fig. 3). Notably, these GPIIIa expression levels were not affected by LZD treatment during differentiation.

LZD Increases Phosphorylation of MLC2 on MEG-01 Cells Several studies suggest that proplatelet formation is regulated by the Rho/Rho-associated protein kinase
(ROCK) pathway, and that MLC2 plays a critical role in this process. $^{22,24)}$ Therefore, to investigate the impact of LZD on the development of proplatelets from megakaryocytes, MLC2 phosphorylation levels were measured in LZD-treated MEG-01 cells via Western blot analysis. PAN was previously reported to significantly increase MLC2 phosphorylation in MEG-01 cells and was therefore utilized as a positive control. ${ }^{22)}$ LZD treatment resulted in a dose-dependent increase in MLC2 phosphorylation, and cells exposed to a high concentration $(200 \mu \mathrm{M})$ of LZD exhibited similar levels of MLC2 phosphorylation as the PAN-treated control cells (Fig. 4). Furthermore, while treatment with $20 \mu \mathrm{M}$ of LZD did not result in a statistically significant increase in MLC2 phosphorylation, there was a trend towards increased phosphorylation in this population.

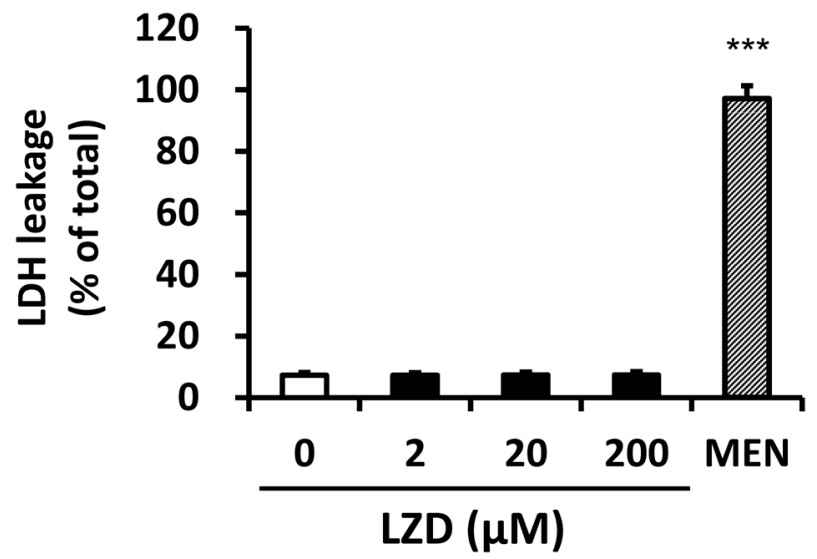

Fig. 1. Effect of Linezolid (LZD) on the Release of Lactate Dehydrogenase (LDH) from Platelets in Rat Platelet-Rich Plasma (PRP)

PRP samples were treated with or without LZD (2-200 $\mu \mathrm{M})$ for $4 \mathrm{~h}$. Menadione (MEN; $40 \mu \mathrm{M}$ ) was used as a positive control. Each value is expressed as a percentage of total activity. The data are expressed as the mean \pm S.E. of the results from five experiments using five animals each. Dunnett's test was utilized for analyses of statistical significance. $* * * p<0.001$ indicates a significant difference from the control group.

\section{HEL}

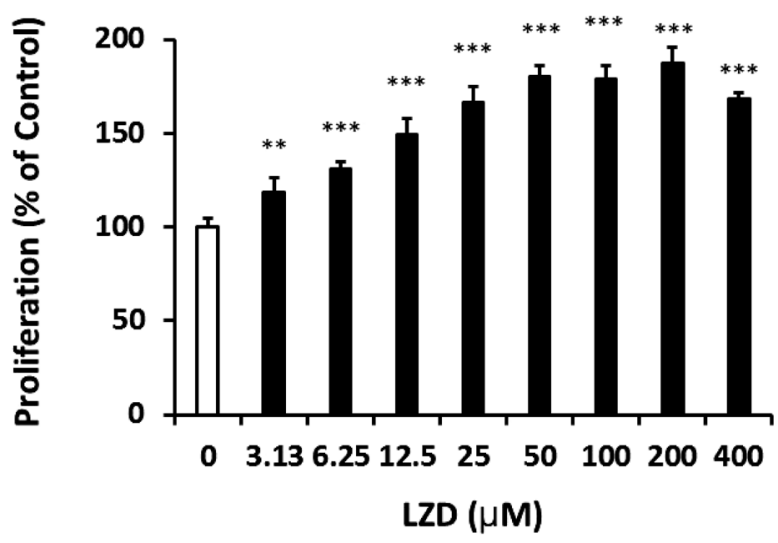

MEG-01

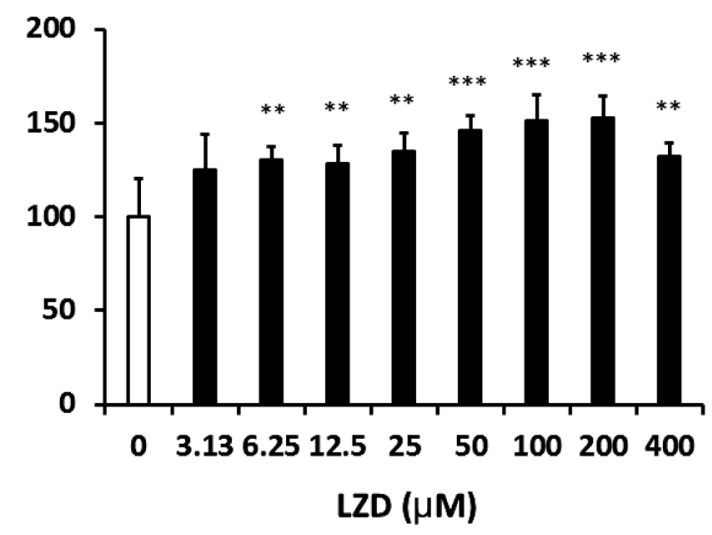

Fig. 2. Effect of LZD on the Proliferation of HEL and MEG-01 Cells

HEL and MEG-01 cells were treated with or without LZD (2-400 $\mu \mathrm{M})$ for $3 \mathrm{~d}$. Each value is expressed as a percentage of the control group (100\%). Data are expressed as the mean \pm S.D. of the results from five experiments. Dunnett's test was utilized for analyses of statistical significance. $* * p<0.01$ and $* * * p<0.001$ indicate significant differences from the control group. 
HEL

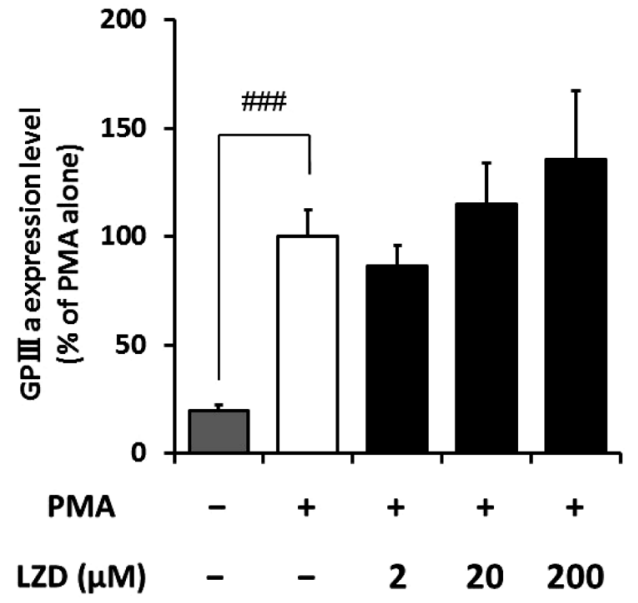

MEG-01

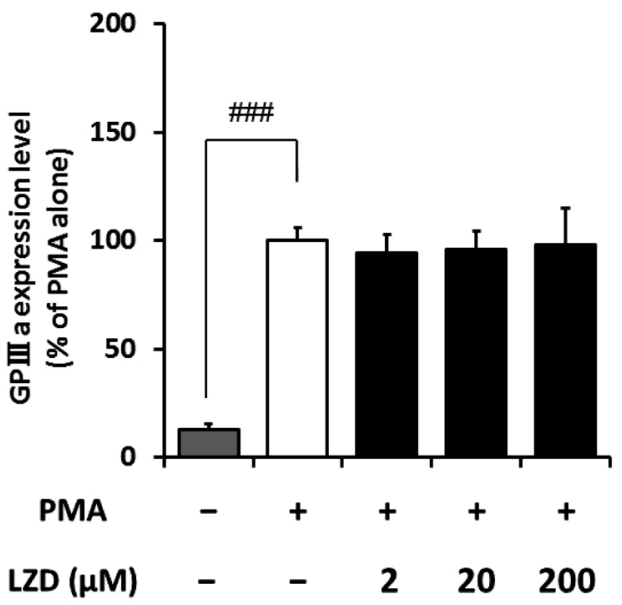

Fig. 3. Effect of LZD on the Megakaryocytic Differentiation of HEL and MEG-01 Cells

HEL and MEG-01 cells were co-treated with phorbol 12-myristate 13-acetate (PMA; 10nM) and LZD ( $0-200 \mu \mathrm{M})$ for $3 \mathrm{~d}$. Each value is expressed as a percentage of the PMA alone control group (100\%). Data are expressed as the mean \pm S.D. of the results of four experiments. Dunnett's test was utilized for analyses of statistical significance. ${ }^{\# \#} p<0.001$ indicates a significant difference from the untreated control group.

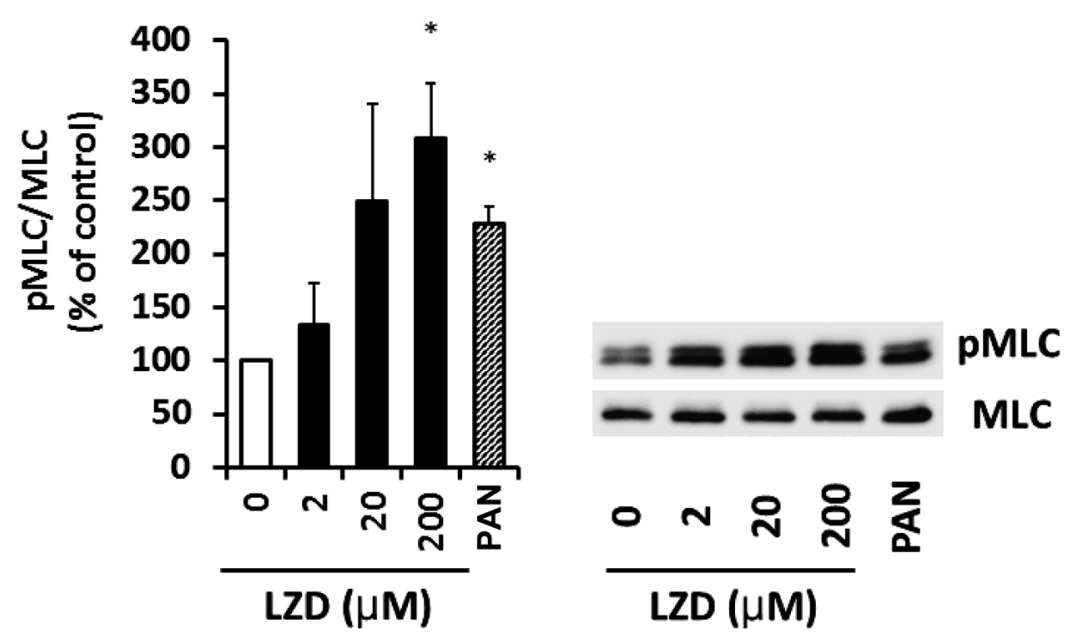

Fig. 4. Effect of LZD on Myosin Light Chain 2 (MLC2) Phosphorylation in MEG-01 Cells

MEG-01 cells were treated with or without LZD $(2-200 \mu \mathrm{M})$ for $24 \mathrm{~h}$. Cells treated with panobinostat (PAN; 20nM) were used as a positive control. Total MLC2 and phosphorylated MLC2 levels were determined by Western blot analysis. Each value is expressed as a percentage of the control group (100\%). Data are presented as the mean \pm S.D. of the results of three experiments. Dunnett's test was utilized for analyses of statistical significance. $* p<0.05$ indicates a significant difference from the control group.

\section{DISCUSSION}

Platelets are produced from hematopoietic stem cells (HSCs) via various biological processes. ${ }^{25,26)}$ HSCs differentiate in a stepwise fashion as follows: from the burst-forming units erythroid/megakaryocytes (BFU-E/M) to colony-forming unit megakaryocytes (CFU-MK), megakaryoblasts, and megakaryocytes. After maturation, megakaryocytes produce and subsequently release proplatelets. Released platelets then circulate in the bloodstream for 7-10 d and are trapped within the liver and spleen. ${ }^{27,28)}$ Platelet numbers are maintained by modulation of the production and destruction processes, and enhanced consumption/destruction or reduced production of platelets results in the development of thrombocytopenia. We therefore hypothesized that the mechanism of LZD-induced thrombocytopenia is due to one or both of these effects.

First, we investigated the impact of LZD on platelet destruction by measuring the level of LDH leakage from plate- lets in rat PRP upon treatment with varying concentrations of LZD. In the clinical setting, patients with VRE and MRSA infections are treated with $600 \mathrm{mg}$ LZD twice daily. When healthy volunteers received this dosage, the maximum steady state plasma concentration $\left(C_{\max }\right)$ was approximately $\left.60 \mu \mathrm{M}^{29}\right)$ In contrast, patients with renal dysfunction that received this dosage reached a $C_{\max }$ of $200 \mu \mathrm{M}$ and developed thrombocytopenia. ${ }^{14)}$ In this study, we therefore chose to utilize a maximum LZD concentration of $200 \mu \mathrm{m}$; however, even at this concentration LZD was not cytotoxic towards platelets (Fig. 1), indicating that the clinical application of this antimicrobial does not enhance platelet destruction.

Next, we focused on examining the effects of LZD on the in vitro proliferation and differentiation of erythroleukemia/ megakaryoblastic cells, which are the intermediate steps of the platelet production process, using the HEL and MEG-01 cell lines. Previous studies demonstrated that HEL cells can be induced to differentiate into megakaryocytic or erythroid 
cells via PMA or hemin treatment, respectively. ${ }^{30,31)}$ Thus, HEL cells can be regarded as the corresponding BFU-E/M. Meanwhile, MEG-01 cells, which can be considered differentiated megakaryoblasts, can also be induced to differentiate into megakaryocytes upon treatment with PMA, resulting in the production of platelet-like particles. ${ }^{32)}$ This PMA-mediated differentiation of HEL and MEG-01 cells is accompanied by an increase in the expression level of the megakaryocyte marker GPIIIa. Notably, we observed an LZD concentrationdependent increase in the proliferation of both cell lines upon exposure to LZD (Fig. 2); however, there were no differences in the GPIIIa mRNA expression levels of cells treated with PMA alone and those co-treated with LZD and PMA (Fig. 3), indicating that LZD does not effect the differentiation of these cell lines. These data therefore suggest that LZD-induced thrombocytopenia is not due to a defect in the proliferation/ differentiation of BFU-E/M and megakaryoblasts during platelet production.

Finally, we investigated the effect of LZD on platelet release, the final step of the platelet production process. Phosphorylation of MLC2, which is regulated by Rho guanosine 5'-triphosphatase (GTPase) family protein and their effector, such as RhoA, Cdc42, Rac1, PAK1 and ROCK1, is a critical step in this process, ${ }^{22,24)}$ and increased MLC2 phosphorylation results in suppression of platelet release. PAN is a histone deacetylase inhibitor used for treatment of hematologic cancers. Notably, the primary adverse side effect of this compound is the induction of thrombocytopenia resulting from the suppression of platelet release via increased MLC2 phosphorylation. ${ }^{22)}$ We therefore assessed the effect of LZD treatment on MLC2 phosphorylation in MEG-01 cells by Western blot analysis. Consistent with previous findings, ${ }^{22)}$ MLC2 phosphorylation was upregulated in the presence of PAN (Fig. 4). Likewise, LZD treatment resulted in a dose-dependent increase in MLC2 phosphorylation, with cells treated with $200 \mu \mathrm{M}$ of LZD exhibiting a 3.1-fold increase in MLC2 phosphorylation compared to that of the control group. These findings therefore suggest that, similar to PAN, LZD induces thrombocytopenia by suppressing platelet release via an increase in MLC2 phosphorylation.

LZD exhibits excellent tissue penetration. Indeed, in a previous study, the penetration efficacy of LZD into bone and muscle was 60 and 94\%, respectively, at 20 min post-infusion. ${ }^{4)}$ Meanwhile, Komatsu et al. reported LZD penetration efficacies of 88 and $84 \%$ into the bone marrow and iliopsoas muscles of rabbits, respectively, at $0.33 \mathrm{~h}$ post-injection. ${ }^{33)}$ Moreover, the LZD concentration was reported to be 1.6-fold higher in the cerebrospinal fluid than in the plasma of patients with central nervous system infections. ${ }^{3)}$ Based on these reports, it was predicted that LZD would rapidly distribute into bone marrow, and at nearly the same concentration as in plasma, and thereby inhibit platelet production by increasing MLC2 phosphorylation. Indeed, we found that enhanced MLC phosphorylation occurred at $20 \mu \mathrm{M}$ of LZD, which was markedly less than the $C_{\max }$ achieved in healthy volunteers receiving $600 \mathrm{mg}$ LZD.

The action mechanism of LZD to increase MLC2 phosphorylation in MEG-01 cell remains unknown. However, considering from several reports, megakaryocyte might express organic anionic transporter polypeptide (OATP) $2 \mathrm{~B} 1,{ }^{34}$ ) which mediate uptake of LZD. ${ }^{35)}$ Intracellular LZD might act as reported in PAN, which induce acetylation of tubulin ${ }^{36)}$ or reduce the protein expression of $\mathrm{CDC} 42$, Rac1, and RhoA. ${ }^{22}$ ) Also, the intracellular signaling pathways that cause the increase of MLC phosphorylation contain Cdc42/Rac1/PAK pathway via MLC kinase, and Rho/Rock pathway via myosin phosphatase. ${ }^{22,24)}$ Further study about the action mechanism of LZD in MEG-01 cell and the relevance of these pathways is considered necessary for the elucidation of LZD-induced thrombocytopenia.

In conclusion, the results presented here suggest that LZD has no direct effect on platelet destruction, but rather induces thrombocytopenia via the suppression of platelet release from mature megakaryocytes, which is the final step in the platelet production process. Our findings may facilitate the development of strategies to treat and/or prevent LZD-induced thrombocytopenia.

Acknowledgment We would like to thank Editage for providing English language editing.

Conflict of Interest The authors declare no conflict of interest.

\section{REFERENCES}

1) Shinabarger D. Mechanism of action of the oxazolidinone antibacterial agents. Expert Opin. Investig. Drugs, 8, 1195-1202 (1999).

2) Conte JE Jr, Golden JA, Kipps J, Zurlinden E. Intrapulmonary pharmacokinetics of linezolid. Antimicrob. Agents Chemother., 46, 1475-1480 (2002).

3) Villani P, Regazzi MB, Marubbi F, Viale P, Pagani L, Cristini F, Cadeo B, Carosi G, Bergomi R. Cerebrospinal fluid linezolid concentrations in postneurosurgical central nervous system infections. Antimicrob. Agents Chemother., 46, 936-937 (2002).

4) Lovering AM, Zhang J, Bannister GC, Lankester BJ, Brown JH, Narendra G, MacGowan AP. Penetration of linezolid into bone, fat, muscle and haematoma of patients undergoing routine hip replacement. J. Antimicrob. Chemother., 50, 73-77 (2002).

5) Gee T, Ellis R, Marshall G, Andrews J, Ashby J, Wise R. Pharmacokinetics and tissue penetration of linezolid following multiple oral doses. Antimicrob. Agents Chemother., 45, 1843-1846 (2001).

6) Welshman IR, Sisson TA, Jungbluth GL, Stalker DJ, Hopkins NK. Linezolid absolute bioavailability and the effect of food on oral bioavailability. Biopharm. Drug Dispos., 22, 91-97 (2001).

7) Birmingham MC, Rayner CR, Meagher AK, Flavin SM, Batts DH, Schentag JJ. Linezolid for the treatment of multidrug-resistant, Gram-positive infections: experience from a compassionate-use program. Clin. Infect. Dis., 36, 159-168 (2003).

8) Takahashi Y, Takesue Y, Nakajima K, Ichiki K, Tsuchida T, Tatsumi S, Ishihara M, Ikeuchi $\mathrm{H}$, Uchino M. Risk factors associated with the development of thrombocytopenia in patients who received linezolid therapy. J. Infect. Chemother., 17, 382-387 (2011).

9) Nukui Y, Hatakeyama S, Okamoto K, Yamamoto T, Hisaka A, Suzuki H, Yata N, Yotsuyanagi H, Moriya K. High plasma linezolid concentration and impaired renal function affect development of linezolid-induced thrombocytopenia. J. Antimicrob. Chemother., 68 , 2128-2133 (2013)

10) Pea F, Viale P, Cojutti P, Del Pin B, Zamparini E, Furlanut M. Therapeutic drug monitoring may improve safety outcomes of long-term treatment with linezolid in adult patients. J. Antimicrob. Chemother., 67, 2034-2042 (2012)

11) Lin YH, Wu VC, Tsai IJ, Ho YL, Hwang JJ, Tsau YK, Wu CY, Wu $\mathrm{KD}$, Hsueh PR. High frequency of linezolid-associated thrombocytopenia among patients with renal insufficiency. Int. J. Antimicrob. 
Agents, 28, 345-351 (2006).

12) Attassi K, Hershberger E, Alam R, Zervos MJ. Thrombocytopenia associated with linezolid therapy. Clin. Infect. Dis., 34, 695-698 (2002).

13) Grau S, Morales-Molina JA, Mateu-de Antonio J, Marín-Casino M, Alvarez-Lerma F. Linezolid: low pre-treatment platelet values could increase the risk of thrombocytopenia. J. Antimicrob. Chemother., 56, 440-441 (2005).

14) Tsuji Y, Hiraki Y, Matsumoto K, Mizoguchi A, Kobayashi T, Sadoh S, Morita K, Kamimura H, Karube Y. Thrombocytopenia and anemia caused by a persistent high linezolid concentration in patients with renal dysfunction. J. Infect. Chemother., 17, 70-75 (2011)

15) Ikuta S, Tanimura K, Yasui C, Aihara T, Yoshie H, Iida H, Beppu N, Kurimoto A, Yanagi H, Mitsunobu M, Yamanaka N. Chronic liver disease increases the risk of linezolid-related thrombocytopenia in methicillin-resistant Staphylococcus aureus-infected patients after digestive surgery. J. Infect. Chemother., 17, 388-391 (2011).

16) Sasaki T, Takane H, Ogawa K, Isagawa S, Hirota T, Higuchi S, Horii T, Otsubo K, Ieiri I. Population pharmacokinetic and pharmacodynamic analysis of linezolid and a hematologic side effect, thrombocytopenia, in Japanese patients. Antimicrob. Agents Chemother., 55, 1867-1873 (2011).

17) Visentin GP, Liu CY. Drug-induced thrombocytopenia. Hematol. Oncol. Clin. North Am., 21, 685-696 (2007).

18) Aster RH, Curtis BR, McFarland JG, Bougie DW. Drug-induced immune thrombocytopenia: pathogenesis, diagnosis, and management. J. Thromb. Haemost., 7, 911-918 (2009).

19) Hitron A, Steinke D, Sutphin S, Lawson A, Talbert J, Adams V. Incidence and risk factors of clinically significant chemotherapyinduced thrombocytopenia in patients with solid tumors. J. Oncol. Pharm. Pract., 17, 312-319 (2011).

20) Kim KA, Lee JY, Park KS, Kim MJ, Chung JH. Mechanism of menadione-induced cytotoxicity in rat platelets. Toxicol. Appl. Pharmacol., 138, 12-19 (1996).

21) Cho YS, Kim MJ, Lee JY, Chung JH. The role of thiols in protecting against simultaneous toxicity of menadione to platelet plasma and intracellular membranes. J. Pharmacol. Exp. Ther., 280, 13351340 (1997).

22) Bishton MJ, Harrison SJ, Martin BP, McLaughlin N, James C, Josefsson EC, Henley KJ, Kile BT, Prince HM, Johnstone RW. Deciphering the molecular and biologic processes that mediate histone deacetylase inhibitor-induced thrombocytopenia. Blood, 117, 3658-3668 (2011).

23) Laemmli UK. Cleavage of structural proteins during the assembly of the head of bacteriophage T4. Nature, 227, 680-685 (1970).

24) Chang Y, Auradé F, Larbret F, Zhang Y, Le Couedic JP, Momeux
L, Larghero J, Bertoglio J, Louache F, Cramer E, Vainchenker W, Debili N. Proplatelet formation is regulated by the Rho/ROCK pathway. Blood, 109, 4229-4236 (2007).

25) Séverin S, Ghevaert C, Mazharian A. The mitogen-activated protein kinase signaling pathways: role in megakaryocyte differentiation. $J$. Thromb. Haemost., 8, 17-26 (2010).

26) Chen S, Su Y, Wang J. ROS-mediated platelet generation: a microenvironment-dependent manner for megakaryocyte proliferation, differentiation, and maturation. Cell Death Dis., 4, e722 (2013).

27) Leeksma CH, Cohen JA. Determination of the life of human blood platelets using labelled diisopropylfluorophosphanate. Nature, 175, 552-553 (1955).

28) George JN. Platelets. Lancet, 355, 1531-1539 (2000).

29) MacGowan AP. Pharmacokinetic and pharmacodynamic profile of linezolid in healthy volunteers and patients with Gram-positive infections. J. Antimicrob. Chemother., 51 (Suppl. 2), ii17-ii25 (2003).

30) Hong Y, Martin JF, Vainchenker W, Erusalimsky JD. Inhibition of protein kinase $\mathrm{C}$ suppresses megakaryocytic differentiation and stimulates erythroid differentiation in HEL cells. Blood, 87, 123-131 (1996).

31) Dai W, Murphy MJ Jr. Downregulation of GATA-1 expression during phorbol myristate acetate-induced megakaryocytic differentiation of human erythroleukemia cells. Blood, 81, 1214-1221 (1993).

32) Takeuchi K, Satoh M, Kuno H, Yoshida T, Kondo H, Takeuchi M. Platelet-like particle formation in the human megakaryoblastic leukaemia cell lines, MEG-01 and MEG-01s. Br. J. Haematol., 100, 436-444 (1998).

33) Komatsu M, Takahata M, Sugawara M, Takekuma Y, Kato T, Ito M, Abe Y, Irie T, Iwasaki N, Minami A. Penetration of linezolid into rabbit intervertebral discs and surrounding tissues. Eur. Spine J., 19, 2149-2155 (2010).

34) Niessen J, Jedlitschky G, Grube M, Bien S, Schwertz H, Ohtsuki S, Kawakami H, Kamiie J, Oswald S, Starke K, Strobel U, Siegmund W, Rosskopf D, Greinacher A, Terasaki T, Kroemer HK. Human platelets express organic anion-transporting peptide 2B1, an uptake transporter for atorvastatin. Drug Metab. Dispos., 37, 1129-1137 (2009).

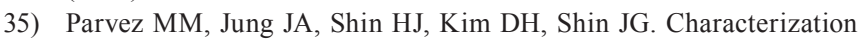
of 22 antituberculosis drugs for inhibitory interaction potential on organic anionic transporter polypeptide (OATP)-mediated uptake. Antimicrob. Agents Chemother., 60, 3096-3105 (2016).

36) Iancu-Rubin C, Gajzer D, Mosoyan G, Feller F, Mascarenhas J, Hoffman R. Panobinostat (LBH589)-induced acetylation of tubulin impairs megakaryocyte maturation and platelet formation. Exp. Hematol., 40, 564-574 (2012). 